\title{
INFILTRATION-EXFILTRATION SYSTEMS DESIGN UNDER HYDROLOGICAL UNCERTAINTY
}

\author{
ANITA RAIMONDI, MARIANA MARCHIONI, UMBERTO SANFILIPPO \& GIANFRANCO BECCIU \\ Politecnico di Milano, Italy
}

\begin{abstract}
The current scenario of urban drainage management encourages the use of sustainable urban drainage systems (SUDSs) acting on runoff volume, peak flow and quality standards. Infiltration-exfiltration systems (IES) are part of SUDSs: they are composed of a high permeability surface and a structure that functions as a reservoir; depending on site characteristics, stormwater can be infiltrated on subsoil, drained or a combination of both. IES design consists basically of sizing the reservoir layer depth according to rainfall, soil and drainage characteristics considering a maximum drainage time between 24 and 72 hours. If long records of rainfall data are available, continuous simulations are performed, otherwise the so called "design event" method is used. It considers a single rainfall event, neglecting the possibility that the storage capacity can be partially filled from previous rainfalls. This paper proposes an analytical probabilistic approach for IES design, combining the simplicity of "design event" methods and the statistical reliability of continuous simulations. It considers the possibility of pre-filling of the reservoir layer from more than one previous event, a key aspect for the correct design of low release structures as IES. The approach has been tested applying proposed equations to a case study, in Milan, Italy, and comparing the results with those from the continuous simulation of recorded data.

Keywords: infiltration-exfiltration systems, hydrological uncertainty, sustainable urban drainage systems, pre-filling, analytical probabilistic modelling.
\end{abstract}

\section{INTRODUCTION}

A characteristic of climate change is the increases of heavy rainfalls characterized by short durations and high intensities. These phenomena, especially on urbanized catchments, causes frequent flood and considerable economic damages. The increase of impervious surfaces, typical of urban areas, decreases soil infiltration and evapotranspiration, so increasing the runoff volume drained to the stormwater drainage system. To avoid the overload of the networks in last decades stormwater source management is encouraged and sometimes mandatory. SUDSs allow retention or detention of stormwater on its source, reducing peak flows, runoff volumes and in some cases the pollution load also providing amenity and biodiversity opportunities into the urban context. Despite their benefits, SUDSs are not always easy to implement and develop in city centre characterized by a high urban density, where retrofitting is generally more expensive and may be limited to few urban spaces. The use of permeable pavements can be effective because it doesn't require any additional space, but it is generally limited to car parks and low traffic roads (Marchioni and Becciu [1]).

IESs are a good trade-off to limit the adaptations to road gutters, that are less stressed by dynamic loads; they are linear street side channels composed of a permeable surface layer and a gravel and sand layer and an underdrain if necessary. Their use may achieve several goals: limiting runoff discharged into the drainage system, since part of rainwater can be infiltrated; reducing peak flow into the network for the temporary storage inside the permeable layers; removing pollutants through filtration, sedimentation, adsorption, biodegradation and volatilization. Moreover, IES avoid ponding, promote aquifer recharge and reduce inlet maintenance. 
Initial researches on permeable pavements in 1970s were mostly conducted on laboratory normally using rainfall simulation (Pratt [2]), while first full-scale tests were performed starting from the 1980s (Hogland et al. [3], Pratt [4], Pratt et al. [5], Legret et al. [6], Legret and Colandini [7], Pagotto et al. [8], Asaeda and $\mathrm{Ca}$ [9], Schlüter and Jefferies [10], Brattebo and Booth [11], Dreelin et al. [12], Morgenroth et al. [13], Newman et al. [14]). Results from these studies show a great variability in stormwater capture efficiency, strictly due to differences in design and climate conditions.

With reference to IES, different research analysed their performances, testing their potential effectiveness in terms of peak flow and volume reduction (Marchioni and Becciu [15]) and pollutant load removal (Teng and Sansalone [16], Sansalone and Teng [17]). Traditional methods, based on design storm event, are unreliable because they just neglect the possibility that the structure is partially pre-filled and that, therefore, the whole capacity is not available at the beginning of the design event.

In this paper, an analytical probabilistic model to analyse the efficiency of IES in terms of their capability to cope with ponding along streets sides has been developed. This kind of models have been proposed at first by Eagleson [18], [19] and Adams and Papa [20] as alternative to continuous simulations to model rainfall-runoff transformation. They have been applied to urban drainage systems to analyse runoff volume and floods peaks (Guo and Adams [21], [22], Guo et al. [23]), stormwater detention storages (Guo and Adams [24], [25], Bacchi et al. [26], Balistrocchi et al. [27], Raimondi and Becciu, [28], [29]; Becciu and Raimondi [30]-[33]) and recently have been used to estimate the efficiency of SUDSs; in particular, analytical probabilistic approaches have been used to analyse green roofs (Zhang and Guo [34], [35], Guo [36], Raimondi and Becciu [37]), rainwater harvesting systems (Guo and Baetz [38], Raimondi and Becciu [39]-[41], Becciu et al. [42]), infiltration trenches (Guo and Gao [43]), bioretention systems (Zhang and Guo [44]), permeable pavements (Zhang and Guo [45]).

These models derive analytical equations of the variable of interest from the probabilistic distribution function (PDF) of rainfall event characteristics and the mathematical representations of the hydrologic processes; they have the great advantage that it is easy to apply them to different kinds of structures under different climate conditions.

Their limitation is that just two rainfall events have been considered and the system has been assumed fully filled at the end of the first event of the current cycle (Howard [46], Loganathan and Delleur [47], Adams and Papa [20]).

Raimondi and Becciu [28] discussed the number of chained events to be considered in the model: they concluded that, for long IETD and high outflow rates, two chained rainfall events may be acceptable; for low outflows facilities or when strict limitations on discharges in the downstream drainage system are imposed, Authors suggested to assume three chained rainfall events to consider the contribution to outflow of pre-filling volumes from previous events.

In Raimondi and Becciu [37], the authors developed a model to consider a chain of $\mathrm{N}$ rainfall events; it has been successfully applied to green roofs and in this paper has been tested on IESs.

The model adapted to an IES is then applied to a case study; the influence of simplifying assumptions of the model on results has been tested and discussed; the accuracy of the proposed approach has been validated by comparing results from analytical equations with those obtained from the continuous simulation of real data. 


\section{HYDROLOGICAL MODELING}

IESs are placed on road gutters to receive runoff from streets and infiltrate it into the underlying layer, to the native soil and/or the drainage system. A typical IES is composed of a permeable surface layer, followed by a gravel aggregate layers that function as a reservoir. A general scheme of the system has been proposed on Fig. 1.

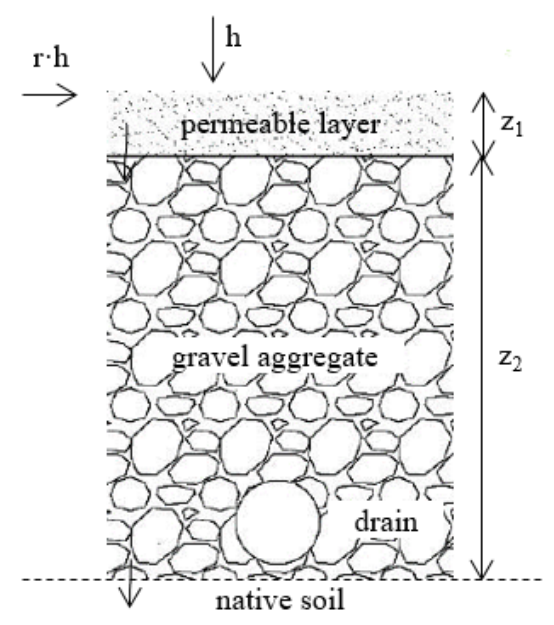

Figure 1: Scheme of an infiltration-exfiltration system.

The permeable surface layer must allow water to infiltrate; therefore, it has a high porosity structure with open and interconnected pores where water and air can pass through; infiltration must be fast enough to avoid the possibility of significant ponding for most of the rainfall events. Both porous asphalt and pervious concrete are suitable for this layer. The gravel aggregate layer must have a high void rate, to perform as a reservoir. But the high void content results on less strength; for this reason, IES are normally applied in street sides. The gravel aggregate layer is usually equipped with an overflow control device so that the water level inside the stone reservoir cannot rise to the pavement level or the surface of the IES during any large storm events. For systems without underdrains, the in-situ soil needs to be highly permeable and with low clay contents (generally less than $30 \%$, U.S. EPA [48]).

Surface runoff rarely occurs, thanks to the high permeability of the surface layer (Brattebo and Booth [11], Collins et al. [49]). Inflow to IES can be trapped by small depressions on the surface or adsorbed by the permeable surface layer; the rest is infiltrated into the gravel aggregate layer, and from its bottom can percolate to the underlying soil. When inflow rate into gravel aggregate layer exceeds infiltration capacity of natural soil, storage occurs, and water level of stone reservoir rises. If storage capacity is then fulfilled, rainwater can either be drained away through underdrain (if installed in the system) or flow away over the surface of the system as surface outflow. After a rainfall event has come to the end, rainwater stored into the IES is depleted by both percolation through the bottom of the gravel aggregate layer and evaporation.

Water balance for an IES is represented by the following equation, usually expressed in millimetres of water over the system's surface area:

$$
I=F+W+R
$$


where $I$ represents the inflow into the structure, $R$ the outflow from the IES, $F$ the infiltration into the underlaying soil and $W$ the stored rainwater volume. Evaporation is neglected in eqn (1) since it is generally negligible in comparison to infiltration (Nemirovsky et al. [50]). If the system is equipped with underdrains, the outflow $R$ is the sum of the volumes of the surface outflow and drain outflow; for IESs without underdrains $R$ is the volume of surface outflow from the system.

Rainwater stored into the IES can vary between zero and $W_{\max }$, that is the retention capacity of the system. For IESs without underdrains, retention capacity $W_{\text {max }}$ consists of three parts: surface depressions and void space of the permeable surface layer, and void space of the gravel aggregate layer.

In an IES with underdrain, the stormwater held in the void space of the surface permeable layer and in the void space of gravel aggregate layer which is above the underdrains can be quickly drained away through the underdrains. Therefore, the retention capacity of the system only consists of the surface depressions plus the void space of the part of the stone reservoir which is below the underdrains.

Inflow to IES $I$ incudes surface runoff from contributing impervious areas $(r \cdot h)$ and rainwater directly falling onto the structure $(h)$ :

$$
I=h+r \cdot h,
$$

where $r=$ ratio between the contributing impervious area and the permeable IES area.

Here, for simplicity, it has been considered that the whole rainfall from the contributing area is collected into the IES. Moreover, despite its random nature (Becciu and Paoletti [51]), the runoff coefficient has been assumed equal to one (completely impervious contributing area).

In addition, infiltration capacity of surface permeable layer and gravel aggregate layer has been assumed to be always greater than inflow rate into the system.

To test the effectiveness of IES as SUDS, an analytical probabilistic model has been proposed. Basically, it consists in estimating the Probability Distribution Functions (PDFs) of the variable of interest from the PDFs of the input variables, which are the rainfall event characteristics, coupled to the mathematical representations of the hydrologic processes occurring in the IES.

Input rainfall variables are rainfall depth, rainfall duration and interevent time; they are considered independent and exponentially distributed. To identify independent events from a continuous series of rainfalls, a minimum interevent time has been defined (IETD). If interevent time between two consecutive rainfall events is lower than IETD then the two storms are joined in a single event, otherwise they are considered independent. In literature, different methods to select IETD have been proposed: estimating the autocorrelation coefficient of observations sample, choosing the values for which the coefficient of variation tends to one, evaluating the relationship between IETD and the average number of rainfall events. In practice, IETD must be related to catchment response characteristic; generally, shorter IETD are suggested for small urban catchment with quick concentration times while for large rural catchment IETD can be also of several hours.

Different studies highlighted as exponential PDF provides a good fit to frequency histograms of main rainfall characteristics (Adams et al. [52], Eagleson [18], Bedient and Huber [53]). Bacchi et al. [26] tested that, for most of the Italian basins, the Weibull probability distribution function better fits the frequency distribution of meteorological input variables than the exponential probability distribution function; however, its use would involve a considerable complication in the integration of the equations. Becciu and Raimondi [30] verified that the double-exponential probability distribution function well fits the 
frequency distribution of observed data for main rainfall characteristic parameters; such distribution may be easily integrated but derived expressions are more complex. Moreover, its application to a case study highlighted that the use of the double-exponential probability distribution function little improves the accuracy of results and that the bias due to the use of the exponential probability distribution function is. In particular, the PDFs of rainfall depth, rainfall duration and interevent time are, respectively:

$$
\begin{gathered}
f_{h}=\xi \cdot e^{-\xi \cdot h}, \\
f_{\theta}=\lambda \cdot e^{-\lambda \cdot \theta}, \\
f_{d}=\psi \cdot e^{-\psi \cdot(d-I E T D)},
\end{gathered}
$$

where $\xi=1 / \mu_{h} ; \lambda=1 / \mu_{\theta} ; \psi=1 /\left(\mu_{d}-\right.$ IETD $)$. The parameters $\mu_{h}, \mu_{\theta}$ and $\mu_{d}$ are the mean values of respectively rainfall depth, rainfall duration and interevent time.

\section{METHODOLOGY}

For a correct design of an IES, outflow discharge should be avoided (full underlying soil infiltration) or limited keeping into account the downstream network capacity and/or the discharge limitations imposed by law and regulations. To estimate overflow probability from an IES, water content in the system at the end of a generic rainfall event must be calculated. The computational scheme can be summarized as follows:

$$
W_{i}=\left\{\begin{array}{cc}
W_{i-1}-f \cdot d_{i}+I_{i}-f \cdot \theta_{i} & \text { Condition }_{1} \\
I_{i}-f \cdot \theta_{i} & \text { Condition }_{2} \\
W_{\max } & \text { Condition }_{3} \text { Condition }_{4} \\
0 & \text { Otherwise }
\end{array}\right.
$$

Condition $_{1}: W_{i-1}-f \cdot d_{i}>0 ; 0<W_{i-1}-f \cdot d_{i}+I_{i}-f \cdot \theta_{i}<W_{\max }$

Condition $_{2}: W_{i-1}-f \cdot d_{i} \leq 0 ; 0<I_{i}-f \cdot \theta_{i}<W_{\max }$

Condition $_{3}: W_{i-1}-f \cdot d_{i} \leq 0 ; I_{i}-f \cdot \theta_{i} \geq W_{\text {max }}$

Condition $_{4}: W_{i-1}-f \cdot d_{i}>0 ; W_{i-1}-f \cdot d_{i}+I_{i}-f \cdot \theta_{i} \geq W_{\text {max }}$,

for $i=1, \ldots, N$ where $N$ is the number of considered rainfall events.

Water content for $i=0$, that is $W_{0}$, is:

$$
W_{0}=\left\{\begin{array}{cc}
I_{0}-f \cdot \theta_{0} & 0<I_{0}-f \cdot \theta_{0}<W_{\max } \\
W_{\max } & I_{0}-f \cdot \theta_{0} \geq W_{\max } \\
0 & I_{0}-f \cdot \theta_{0} \leq 0
\end{array} .\right.
$$

With reference to eqn (7):

Condition $_{l}$ expresses the case of pre-filling from previous rainfall event at the end of the considered event and this does not produce runoff.

Condition $_{2}$ expresses the case in which there is no pre-filling from previous rainfall event at the end of the considered event and this does not produce runoff.

Condition $_{3}$ expresses the case in which there is no pre-filling from previous rainfall event at the end of the considered event and this produces runoff.

Condition $_{4}$ expresses the case of pre-filling from previous rainfall event at the end of the considered event and this produces runoff.

Variable $f$ in eqns (7) and (8) represents infiltration rate; it has been assumed constant and equal to the saturated hydraulic conductivity of the native soils.

Overflow from an IES is a random variable strictly depending on rainfall characteristics, infiltration rate of native soils, and maximum storage capacity of the system. It results: 


$$
R_{i}=\left\{\begin{array}{cc}
W_{i-1}-f \cdot d_{i}+I_{i}-f \cdot \theta_{i}-W_{\max } & \text { Condition }_{1} \\
I_{i}-f \cdot \theta_{i}-W_{\max } & \text { Condition }_{2} ; \text { Condition }_{3} \\
W_{\max }-f \cdot d_{i}+I_{i}-f \cdot \theta_{i}-W_{\max } & \text { Condition }_{4} \\
0 & \text { Otherwise }
\end{array} .\right.
$$

Condition $_{1}: W_{i-1}<W_{\max } ; W_{i-1}>f \cdot d_{i} ; W_{i-1}-f \cdot d_{i}+I_{i}-f \cdot \theta_{i}>W_{\max }$

Condition $_{2}: W_{i-1}<W_{\text {max }} ; W_{i-1} \leq f \cdot d_{i} ; I_{i}-f \cdot \theta_{i}>W_{\max }$

Condition $_{3}: W_{i-1} \geq W_{\max } ; W_{\max } \leq f \cdot d_{i} ; I_{i}-f \cdot \theta_{i}>W_{\max }$

Condition $_{4}: W_{i-1} \geq W_{\max } ; W_{\max }>f \cdot d_{i} ; W_{\max }-f \cdot d_{i}+I_{i}-f \cdot \theta_{i}>W_{\max }$,

for $i=1, \ldots, N$ where $N$ is the number of considered rainfall events.

Outflow for $i=0$, that is $R_{0}$, results:

$$
R_{0}=\left\{\begin{array}{cc}
I_{0}-f \cdot \theta_{0}-W_{\max } & I_{i}-f \cdot \theta_{i}>W_{\max } \\
0 & \text { Otherwise }
\end{array}\right.
$$

With reference to eqn (9):

Condition $_{1}$ expresses the case in which there is no outflow at event $i-1$, there is pre-filling from event $i-1$ at the beginning of event $i$ and there is runoff from the IES at the end of event $i$;

Condition $_{2}$ expresses the case in which there is no outflow from event $i-1$, there is no prefilling from event $i-1$ at the beginning of event $i$ and there is runoff from the IES at the end of event $i$

Condition $_{3}$ expresses the case in which there is outflow from event $i-1$, there is no prefilling from event $i-1$ at the beginning of event $i$ and there is runoff from the IES at the end of event $i$;

Condition $_{4}$ expresses the case in which there is outflow from event $i-1$, there is pre-filling from event $i-1$ at the beginning of event $i$ and there is runoff from the IES at the end of event $i$.

With reference to the derived probability distribution theory (Benjamin and Cornell [54]), outflow PDF from the system can be derived from PDFs of rainfall depth $h$, rainfall duration $\theta$ and interevent time $d$. It has been estimated setting $h=h_{i}=h_{i+1}, \theta=\theta_{i}=\theta_{i+1}, d=$ $d_{i}=d_{i+1}$ in eqn (9); this leads to exclude Condition . $_{\text {. }}$

Outflow probability have been estimated distinguishing two different conditions: maximum emptying time, that is time needed to empty the retention capacity when it is full, respectively lower and higher than the minimum interevent time IETD:

- for Case 1, the pre-filling from previous rainfalls at the beginning of the considered event has been excluded with the full storage capacity available;

- for Case 2, the possibility that retention volume is partially filled from previous rainfalls has been analyzed.

The term $I A$ in eqns (2) and (3), representing the stormwater trapped by small surface depressions, has been neglected, since it is generally very low. a threshold outflow volume $\bar{R}$, related for example to downstream discharge constrains into the drainage system, has been used in the calculation.

Case 1: $W_{\text {max }} / f \leq I E T D$ :

$$
P_{R}=P(R>\bar{R})=\int_{h=\frac{W_{\max }+\bar{R}+f \cdot \theta}{1+r}}^{\infty} p_{h} \cdot d h \int_{\theta=0}^{\infty} p_{\theta} \cdot d \theta=\gamma \cdot e^{-\frac{\xi}{1+r} \cdot\left(W_{\max }+\bar{R}\right)},
$$


with: $\gamma=\frac{\lambda \cdot(1+r)}{f \cdot \xi+\lambda \cdot(1+r)}$.

Case 2: $W_{\max } / f>$ IETD:

$$
\begin{gathered}
P_{R}=P(R>\bar{R})=\int_{\theta=0}^{\infty} p_{\theta} \cdot d \theta \quad \int_{h=\frac{W_{\max }+\bar{R}+f \cdot \theta}{1+r}}^{\infty} p_{h} \cdot d h \\
+\sum_{i=2}^{N}\left[\int_{\theta=0}^{\infty} p_{\theta} \cdot d \theta \int_{d=I E T D}^{\frac{W_{\max }+(i-2) \cdot f \cdot d}{(i-1) \cdot(1+r)}+\frac{f \cdot \theta}{1+r}} p_{d}^{f} \cdot d d \int_{h=\frac{W_{\max }+\bar{R}+(i-1) \cdot f \cdot d}{i \cdot(1+r)}+\frac{f \cdot \theta}{1+r}}^{f} p_{h} \cdot d h\right] \\
=\gamma \cdot\left\{e^{-\frac{\xi}{1+r} \cdot\left(W_{\max }+\bar{R}\right)}-\psi \cdot(1+r) \cdot \sum_{i=2}^{N}\left[(i-1) \cdot \beta_{i} \cdot e^{-\frac{\xi}{(1+r) \cdot(i-1)} \cdot\left[f \cdot I E T D \cdot(i-2)+w_{\max }\right]}+\right.\right. \\
i \cdot \beta_{i}^{*} \cdot e^{-\frac{\xi}{i \cdot(1+r)} \cdot\left[\bar{R}+W_{\max }+f \cdot I E T D(i-1)\right]}+\xi \cdot f \cdot \beta_{i} \cdot \beta_{i}^{*} \cdot \\
\left.\left.e^{\psi \cdot I E T D+\frac{\psi}{f} \cdot\left[\bar{R} \cdot(i-1)-w_{\max }\right]-\frac{\xi}{1+r} \cdot\left(2 \cdot \bar{R}+w_{\max }-i \cdot \bar{R}\right)}\right]\right\}
\end{gathered}
$$

where: $\beta_{i}=\frac{1}{\xi \cdot f \cdot(i-2)+\psi \cdot(i-1) \cdot(1+r)} ; \beta_{i}^{*}=-\frac{1}{i \cdot \psi \cdot(1+r)+(i-1) \cdot \xi \cdot f}$.

\section{CASE STUDY}

The proposed IES model has been applied to a case study considering the cross section indicated on Fig. 1 and Milan (Italy) rainfall data. The system has a surface permeable layer of depth $z_{1}=10[\mathrm{~cm}]$ and porosity $n_{1}=0.15[-]$; a gravel aggregate layer of depth $z_{2}=$ $60[\mathrm{~cm}]$ and porosity $n_{2}=0.35[-]$ has been considered. So, the maximum retention capacity results equal to $W_{\max }=z_{1} \cdot n_{1}+z_{2} \cdot n_{2}=21.5[\mathrm{~cm}]$. Infiltration capacity of the underlying natural soil has been estimated equal to $f=3.6[\mathrm{~mm} / \mathrm{hour}]$ (it corresponds to a sandy-clay loam with hydraulic conductivity equal to $K=10^{-6}[\mathrm{~m} / \mathrm{s}]$ ). The ration between the impervious contributing area and the infiltration area has been assumed equal to $r=4$. Input rainfalls are those recorded at Milano-Monviso gauge station in the period 19712005. To identify independent rainfall events from the continuous data records, a IETD = 1 [hour] has been used. The main characteristics of rainfall variables mean $\mu$, standard deviation $\sigma$ and coefficient of variation $V$, are reported in Table 1 .

Table 1: Main characteristics of rainfall variables.

\begin{tabular}{|c|c|c|c|}
\hline & $\mu$ & $\sigma$ & $\mathrm{V}=\sigma / \mu$ \\
\hline $\mathrm{h}(\mathrm{mm})$ & 7.62 & 12.40 & 1.63 \\
\hline$\theta$ (hour) & 4.32 & 5.79 & 1.34 \\
\hline $\mathrm{d}$ (hour) & 66.50 & 129.00 & 1.94 \\
\hline
\end{tabular}

The hypothesis of exponential PDF is not perfectly suitable to the experimental data, especially for rainfall depth and interevent time, but the effects on the results have been deeply tested by the authors in [28], concluding that the bias due to its use can be considered negligible. Table 2 contains the correlation coefficients among the three hydrological parameters. Interevent time results are just weakly correlated to the other two variables, while the correlation between rainfall depth and duration is quite high. 
Table 2: Correlation index among rainfall variables.

\begin{tabular}{|c|c|}
\hline$\rho_{\mathrm{h}, \mathrm{d}}(-)$ & 0.01 \\
\hline$\rho_{\theta, \mathrm{h}}(-)$ & 0.70 \\
\hline$\rho_{\mathrm{d}, \theta}(-)$ & 0.01 \\
\hline
\end{tabular}

Eqn (11) has be tested considering the maximum retention capacity $W_{\max }$ varying between zero to 250 [mm] (Fig. 2); the threshold retention capacity $\bar{R}$ has been set equal to zero. Outflow PDF has been estimated considering a single event $i=1$, a couple of events $i=2$ and four chained events $i=4$; the results have been compared with observed frequency calculated considering the whole series of records. The approach of considering a chain of events instead of one improves fitting, since pre-filling from previous rainfall has been considered in the model. But the proposed equation overestimates the probability of overflow for low retention capacities because the effects of the simplifying assumptions are more remarkable. A retention capacity equal to $W_{\max }=215[\mathrm{~mm}]$, that is the case of the considered IES, corresponds to a return period $T=34$ [years] (that can be considered acceptable for design purposes). If a return period of $T=50$ [years] is considered, the overflow probability results equal to $0,02[-]$, that corresponds to a retention capacity equal to $W_{\max }=270[\mathrm{~mm}]$. Always considering a surface permeable layer of depth $z_{1}=10[\mathrm{~cm}]$ and porosity $n_{1}=0.10$, the gravel aggregate layer should be equal to $z_{2}=73[\mathrm{~cm}]$, setting $n_{2}=0.35$.

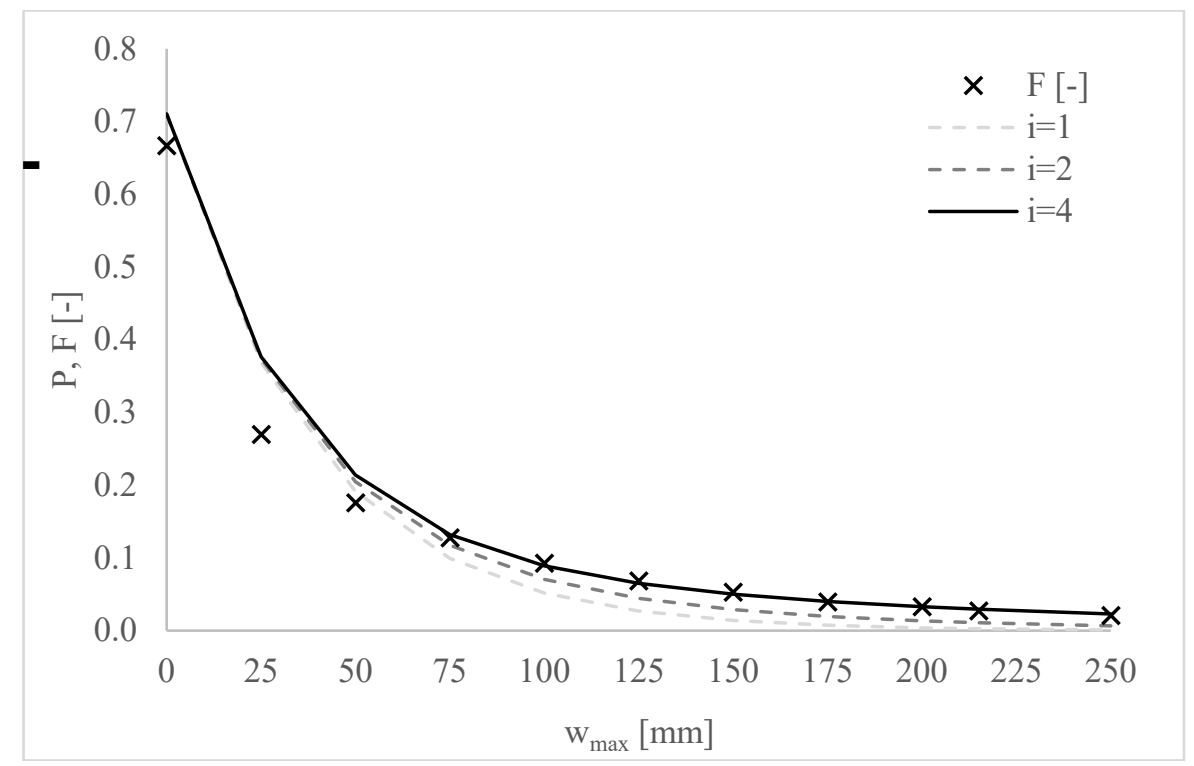

Figure 2: Outflow PDF from an IES varying retention capacity.

\section{CONCLUSIONS}

IESs can be an effective tool for SUDSs, especially in cases where the presence of vehicular traffic prevents the use of permeable pavements for the whole considered area. The proposed 
approach shows good results, compared with frequency analysis of continuous simulation, especially in the usual filed of application (as retention capacity lower than $10(\mathrm{~cm})$ should be avoided in practice). The possibility of considering more than one previous rainfall event into the modelling assures the quality of the results in the application of analytical probabilistic models, even in the cases of low outflow rates characterized by more than two chained rainfall events. Proposed formulas can be useful to designers, because they allow to estimate the maximum retention capacity of an IES, once the design return period has been set, and given the first moments of rainfall depth, rainfall duration and interevent time, the outflow rate, the ratio between the catchment area and the area of the infiltration system.

\section{REFERENCES}

[1] Marchioni, M. \& Becciu, G., Experimental results on permeable pavements in urban areas: A synthetic review. International Journal of Sustainable Development and Planning, 10(6), pp. 806-817, 2015. http://dx.doi.org/10.2495/SDP-V10-N6-806-817.

[2] Pratt, C.J., Sustainable drainage: A review of published material on the performance of various SUDS components. Prepared for the Environment Agency, SUDS Science Group/99705.015, 2004.

[3] Hogland, W., Niemczynowicz, J. \& Wajlman, T., The unit superstructure during the construction period. Science of the Total Environment, 59, pp. 411-424, 1987. http://dx.doi.org/10.1016/0048-9697(87)90464-5.

[4] Pratt, C.J., Use of permeable, reservoir pavement constructions for stormwater treatment and storage for re-use. Water Science and Technology, 39(5), pp. 145-151, 1999. http://dx.doi. org/10.1016/s0273-1223(99)00096-7.

[5] Pratt, C.J., Mantle, J. \& Schofield, P., UK research into the performance of permeable pavement, reservoir structures in controlling stormwater discharge quantity and quality. Water Science and Technology, 32(1), pp. 63-69, 1995.

http://dx.doi.org/10.1016/0273-1223(95)00539-y.

[6] Legret, M., Colandini, V. \& Le Marc, C., Effects of a porous pavement with reservoir structure on the quality of runoff water and soil. Science of the Total Environment, 189-190, pp. 335-340, 1996. http://dx.doi.org/10.1016/0048-9697(96)05228-x.

[7] Legret, M. \& Colandini, V., Effects of a porous pavement with reservoir structure on runoff water: Water quality and fate of heavy metals. Water Science and Technology, 39(2), pp. 111-117, 1999. http://dx.doi.org/10.1016/s0273-1223(99)00014-1.

[8] Pagotto, C., Legret, M. \& Le Cloirec, P., Comparison of the hydraulic behaviour and the quality of highway runoff water according to the type of pavement. Water Research, 34(18), pp. 4446-4454, 2000.

http://dx.doi.org/10.1016/s0043-1354(00)00221-9.

[9] Asaeda, T. \& Ca, V.T., Characteristics of permeable pavement during hot summer weather and impact on the thermal environment. Building and Environment, 35(4), pp. 363-375, 2000. http://dx.doi.org/10.1016/s0360-1323(99)00020-7.

[10] Schlüter, W. \& Jefferies, C., Modelling the outflow from a porous pavement. Urban Water, 4(3), pp. 245-253, 2002. http://dx.doi.org/10.1016/s1462-0758(01)00065-6.

[11] Brattebo, B.O. \& Booth, D.B., Long-term stormwater quantity and quality performance of permeable pavement systems. Water Research, 37(18), pp. 43694376, 2003. https://doi.org/10.1016/S0043-1354(03)00410-X.

[12] Dreelin, E.A., Fowler, L. \& Ronald Carroll, C., A test of porous pavement effectiveness on clay soils during natural storm events. Water Research, 40(4), pp. 799-805, 2006. http://dx.doi. org/10.1016/j.watres.2005.12.002. 
[13] Morgenroth, J., Buchan, G. \& Scharenbroch, B.C., Belowground effects of porous pavements: Soil moisture and chemical properties. Ecological Engineering, 51, pp. 221-228, 2013. http://dx.doi.org/10.1016/j.ecoleng.2012.12.041.

[14] Newman, A.P., Aitken, D. \& Antizar-Ladislao, B., Stormwater quality performance of a macro-pervious pavement car park installation equipped with channel drain based oil and silt retention devices. Water Research, 47(20), pp. 7327-7336, 2013.

http://dx.doi.org/10.1016/j.watres.2013.05.061.

[15] Marchioni, M. \& Becciu, G., Infiltration-exfiltration system for stormwater runoff volume and peak attenuation. International Journal of Safety and Security Engineering, 8(4), pp. 473-483, 2018. http://dx.doi. org/10.2495/SAFE-V8-N4-473-483.

[16] Teng, Z. \& Sansalone J.J., In situ partial exfiltration of rainfall runoff. II: Particle separation. Journal of Environmental Engineering, 130(9), pp. 1008-1020, 2004. https://doi.org/10.1061/(ASCE)0733-9372(2004)130:9(1008).

[17] Sansalone, J.J. \& Teng, Z., Transient rainfall-runoff loadings to a partial exfiltration system: Implications for urban water quantity and quality. Journal of Environmental Engineering, 131(8), 2005.

https://doi.org/10.1061/(ASCE)0733-9372(2005)131:8(1155).

[18] Eagleson, P.S., Climate, soil and vegetation: The distribution of annual precipitation derived from observed storm sequences. Water Resources Research, 14(5), pp. 713721, 1978. https://doi.org/10.1029/WR014i005p00722.

[19] Eagleson, P.S., Dynamics of flood frequency. Water Resources Research, 8(4), pp. 878-898, 1972. https://doi.org/10.1029/WR008i004p00878.

[20] Adams, B. J., \& Papa, F., Urban Stormwater Management Planning with Analytical Probabilistic Models, Wiley: New York, 2000.

[21] Guo, Y. \& Adams, B.J., Hydrologic analysis of urban catchments with event-based probabilistic models. Part I: Runoff volume. Water Resources Research, 34(12), pp. 3421-3431, 1998. https://doi.org/10.1029/98WR02449.

[22] Guo, Y. \& Adams, B.J., Hydrologic analysis of urban catchments with event-based probabilistic models. Part II: Peak discharge rate. Water Resources Research, 34(12), pp. 3433-3443, 1998. https://doi.org/10.1029/98WR02448.

[23] Guo, Y., Liu, S. \& Baetz, B.W., Probabilistic rainfall-runoff transformation considering both infiltration and saturation excess runoff generation processes. Water Resources Research, 48(6), 2012. https://doi.org/10.1029/2011WR011613.

[24] Guo, Y. \& Adams, B.J., Analysis of detention ponds for storm water quality control. Water Resources Research, 35(8), pp. 2447-2456, 1999. https://doi.org/10.1029/1999WR900124.

[25] Guo, Y. \& Adams, B.J., An analytical probabilistic approach to sizing flood control detention facilities. Water Resources Research, 35(8), pp. 2457-2468, 1999. https://doi.org/10.1029/1999WR900125.

[26] Bacchi, B., Balistrocchi, M. \& Grossi, G., Proposal of a semi-probabilistic approach for storage facility design. Urban Water Journal, 5(3), pp. 195-208, 2008. https://doi.org/10.1080/15730620801980723.

[27] Balistrocchi, M., Grossi, G. \& Bacchi, B., An analytical probabilistic model of the quality efficiency of a sewer tank. Water Resources Research, 45(12), 2009. https://doi.org/10.1029/2009WR007822.

[28] Raimondi, A. \& Becciu, G., On pre-filling probability of flood control detention facilities. Urban Water Journal, 12(4), pp. 344-351, 2015.

http://dx.doi.org/10.1080/1573062X.2014.901398. 
[29] Raimondi, A. \& Becciu, G., On the efficiency of stormwater detention tanks in pollutant removal. International Journal of Sustainable Development and Planning, 12, pp. 144-154, 2017. http://dx.doi. org/10.2495/SDP-V12-N1-144-154.

[30] Becciu, G. \& Raimondi, A., Factors affecting the prefilling probability of water storage tanks. WIT Transactions on Ecology and the Environment, vol. 64, WIT Press: Southampton and Boston, pp. 473-484, 2012. http://dx.doi. org/10.2495/WP120411.

[31] Becciu, G. \& Raimondi, A., Probabilistic analysis of spills from stormwater detention facilities. WIT Transactions on the Built Environment, vol. 139, WIT Press: Southampton and Boston, pp.159-170, 2014. http://dx.doi. org/10.2495/UW140141.

[32] Becciu, G. \& Raimondi, A., Probabilistic modeling of the efficiency of a stormwater detention facility. International Journal of Sustainable Development and Planning, 10(6), pp. 795-805, 2015. http://dx.doi. org/10.2495/SDP-V0-N0-1-11.

[33] Becciu, G. \& Raimondi, A., Probabilistic analysis of the retention time in stormwater detention facilities. Procedia Engineering, 119(1), pp.1299-1307, 2015. http://dx.doi.org/10.1016/j.proeng.2015.08.951.

[34] Zhang, S. \& Guo, Y., An analytical probabilistic model for evaluating the hydrologic performance of green roofs. Journal of Hydrologic Engineering, 18(1), pp. 19-28, 2013. https://doi.org/10.1061/(ASCE)HE.1943-5584.0000593.

[35] Zhang, S. \& Guo, Y., Explicit equation for estimating storm-water capture efficiency of rain gardens. Journal of Hydrologic Engineering, 18(12), pp.1739-1748, 2012. https://doi.org/10.1061/(ASCE)HE.1943-5584.0000734.

[36] Guo, Y., Stochastic analysis of hydrologic operation of green roofs. Journal of Hydrologic Engineering, 21(7), 2016. https://doi.org/10.1061/(ASCE)HE.1943-5584.0001371.

[37] Raimondi, A. \& Becciu, G., Performance of green roofs for rainwater control. Water Resources Management, 2020.

[38] Guo, Y. \& Baetz, B.W., Sizing of rainwater storage units for green building applications. Journal of Hydrologic Engineering, 12(2), pp. 197-205, 2007. https://doi.org/10.1061/(ASCE)1084-0699(2007)12:2(197).

[39] Raimondi, A. \& Becciu, G., An analytical probabilistic approach to size cisterns and storage units in green buildings. 11th International Conference on Computing and Control for the Water Industry 2011 - CCWI 2011, pp. 179-184, 2011.

[40] Raimondi, A. \& Becciu, G., Probabilistic design of multi-use rainwater tanks. Procedia Engineering, 70, pp. 1391-1400. 2014. https://doi.org/10.1016/j.proeng.2014.02.154.

[41] Raimondi, A. \& Becciu, G., Probabilistic modelling of rainwater tanks. Procedia Engineering, 89, pp. 1493-1499, 2014. http://dx.doi.org/10.1016/j.proeng.2014.11.437.

[42] Becciu, G., Raimondi, A. \& Dresti C., Semi-probabilistic design of rainwater tanks: A case study in Northern Italy. Urban Water Journal, 15(3), pp. 192-199, 2016. http://dx.doi. org/10.1080/1573062X.2016.1148177.

[43] Guo, Y. \& Gao, T., Analytical equations for estimating the total runoff reduction efficiency of infiltration trenches. Journal of Sustainable Water in the Built Environment, 2(3), 2016. https://doi.org/10.1061/JSWBAY.0000809.

[44] Zhang, S. \& Guo, Y., Stormwater capture efficiency of bioretention systems. Water Resources Management, 28(1), pp. 149-168, 2014. https://doi.org/10.1007/s11269-013-0477-y. 
[45] Zhang, S. \& Guo, Y., An analytical equation for evaluating the stormwater volume control performance of permeable pavement systems. Journal of Irrigation and Drainage Engineering, 141(4), 2015. http://dx.doi. org/10.1061/(ASCE)IR.1943-4774.0000810.

[46] Howard, C.D.D., Theory of storage and treatment plant overflows. Journal of the Environmental Engineering Division, 102(4), pp. 709-722, 1976.

[47] Loganathan, G.V. \& Delleur, J.W., Effects of urbanization on frequencies of overflows and pollutant loadings from storm sewer overflows: A derived distribution approach. Water Resources Research, 20(7), pp. 857-865, 1984. https://doi.org/10.1029/WR020i007p00857.

[48] U.S. EPA, Storm water technology fact sheet: Porous pavement. Report No. EPA 832F-99-023, Washington, DC, 1999.

[49] Collins, K.A., Hunt, W.F. \& Hathaway, J.M., Hydrologic comparison of four types of permeable pavement and standard asphalt in eastern North Carolina. Journal of Hydrologic Engineering, 13(12), pp. 1146-1157, 2008. https://doi.org/10.1061/(ASCE)1084-0699(2008)13:12(1146).

[50] Nemirovsky, E.M., Welker, A.L. \& Lee, R., Quantifying evaporation from pervious concrete systems: Methodology and hydrologic perspective. Journal of Irrigation and Drainage Engineering, 139(4), pp. 271-277, 2013. https://doi.org/10.1061/(ASCE)IR.1943-4774.0000541.

[51] Becciu, G. \& Paoletti, A., Random characteristics of runoff coefficient in urban catchments. Water Science and Technology, 36(8-9), pp. 39-44, 1997.

[52] Adams, B.J., Fraser, H.G., Howard, C.D.D. \& Hanafy, M.S., Meteorological data analysis for drainage system design. Journal of Environmental Engineering, 112(5), pp. 827-848, 1986.

[53] Bedient, P.B. \& Huber, W.C., Hydrology and Floodplain Analysis, 2nd ed., Addison Wesley: New York, 1992.

[54] Benjamin, J.R. \& Cornell, C.A., Solutions Manual to Accompany Probability, Statistics, and Decision for Civil Engineers, McGraw-Hill, 1970. 